\title{
¿Cronograma establecido? Representaciones de maternidad según mujeres profesionales en Lima
}

\section{Tania Pariona Icochea}

Pontificia Universidad Católica del Perú

tania.edit@gmail.com

Este texto busca reflexionar acerca de las concepciones de maternidad de un grupo de mujeres profesionales residentes en Lima. Nos preguntamos cómo se ubican ante la decisión de ser madres y cómo encaja la maternidad en sus proyectos de vida. La investigación se sustenta en entrevistas a veintiséis mujeres profesionales de distintas áreas, en el rango de edad de 28 a 38 años, que no eran madres al momento de la entrevista. Sus respuestas nos muestran un panorama complejo en el cual diversas concepciones de maternidad coinciden en comprenderla como un sacrificio del tiempo de la vida personal y profesional. El afán por equilibrar la vida laboral y profesional con un proyecto de maternidad en un "cronograma establecido» por la presión social hace que las respuestas de estas mujeres sean por momentos contradictorias, y estas dan cuenta de la angustia latente por tener que decidirse entre la maternidad $u$ optar por nuevas formas de vida.

Palabras clave: mujeres profesionales, femineidad, maternidad, cronograma establecido, vida privada. 


\section{Established timeline? Motherhood depictions by professional women in Lima}

ABSTRACT

This text seeks to reflect on the conceptions of motherhood of a group of professional women living in Lima. We ask ourselves, how are they situated before the decision to be mother and how does motherhood fit into their life projects. The research is based on twenty-six interviews to professional women from different areas, in the age range of 28 to 38 years, who were not mothers at the time of the interview. Their answers show us a complex picture where various conceptions of motherhood coincide understanding it as a sacrifice of personal and professional life. The eagerness to balance work and family life with a motherhood project in an "established timeline» by social pressure makes the responses of these women at times contradictory, they also show the latent anguish of having to decide between motherhood or new ways of living.

Keywords: professional women, femininity, motherhood, established timeline, private life. 
El Perú, como otros países de Latinoamérica, presenta cifras aparentemente contradictorias en relación con la fecundidad. Si bien los índices de embarazo adolescente todavía son altos (Torricelli, 2018), la fecundidad en mujeres con educación superior tiende a la baja. El acceso de estas últimas a la educación, la aparición y divulgación de métodos anticonceptivos y de las propuestas feministas vienen cambiando el panorama social. La liberalización de la sexualidad femenina ha sido paulatina, pero evidente. Todo ello tiene como consecuencia que las tasas de natalidad en mujeres de los sectores más educados son cada vez más bajas y la maternidad va dejando de ser entendida como la única (o prioritaria) y máxima vía de la realización femenina. Aramburú y Bustinza (2007) señalan, para el caso peruano, que entre 1977 y 2004 la tasa de fecundidad global en mujeres con mayor educación descendió un 44 por ciento, mientras que la misma tasa en mujeres analfabetas descendió solo un 33 por ciento. Según los autores, la diferencia del inicio de la crianza de los hijos entre las mujeres educadas y las analfabetas es de nueve años. En el caso de las mujeres educadas, estos años a favor les permiten una mayor autonomía.

Esta tendencia se observa en diferentes sociedades. Cepal (2007) señala que la mejora de la salud reproductiva en América Latina ha ido, paradójicamente, al lado del descenso de la fecundidad, donde cada vez hay más mujeres sin hijos, ya sea porque postergan o porque rechazan la maternidad. Esta tendencia deriva de la priorización de otros proyectos de vida, como educarse primero, conseguir trabajo, establecerse profesionalmente, etc. (Therborn, 2007) ${ }^{1}$. Encontrar un compañero con quien tener hijos no se ubica como prioridad o, muchas veces,

Además, hay que señalar la tendencia mundial — que va en aumento- de las «parejas sin hijos» (childless, DINKs - double income, no kids) de las mujeres y varones que no desean ser madres (NoMo - no mother) ni padres (Delgado y Gómez, 2006; Chacón y Tapia, 2017). 
no se logra ${ }^{2}$. Así, por ejemplo, según Montilva (2008, p. 71), para las profesionales de Caracas y Santiago de Chile la maternidad deja de ser el rol femenino fundamental y pasa a ser un acto en sus biografías para el cual requieren mayor preparación y planificación.

En el contexto peruano, según la Encuesta Demográfica y de Salud Familiar - ENDES 2013 (Instituto Nacional de Estadística e Informática, 2014), la tasa de fecundidad nacional sigue un lento descenso (de 2,6\% en el 2009 a 2,4\% en 2013 en el área urbana). En el caso de Lima Metropolitana, este descenso porcentual es más notorio (de $2,1 \%$ en 2009 a $1,9 \%$ en 2013). Por lo contrario, la edad en que las mujeres tienen al primer hijo ha experimentado un ligero incremento. En el intervalo de edad de 25 a 29 años, el aumento fue de $27,3 \%$ en 2009 a $27,6 \%$ en 2013. En el intervalo de edad de 30 a 34 años, el aumento fue de $14,5 \%$ en 2009 a $15 \%$ en 2013, mientras que en el intervalo de 35 a 39 años fue de $9,3 \%$ a $9,7 \%$. Estas cifras muestran un cambio en la fecundidad de las mujeres urbanas en el Perú, que se relaciona, como ya señalamos líneas arriba, con el acceso a métodos anticonceptivos y a cambios en las concepciones sobre la crianza de los hijos.

En este contexto, el presente artículo explora las concepciones sobre la maternidad de un grupo de profesionales residentes en Lima: cómo se ubican ante ella, cómo reaccionan o no ante la presión social por ser madres y qué lugar ocupa en sus proyectos de vida con el fin de entender las razones por las cuales postergan esta decisión.

La metodología de la investigación consistió en entrevistas realizadas a partir de una muestra por conveniencia, según la voluntad de las informantes de participar, que luego dio paso al muestreo por «bola de nieve». Es decir, se buscó que cada informante nos refiriera a otras, en base a sus redes sociales. Se construyó un cuadro de información general de las entrevistadas (Anexo I. Lista de entrevistadas).

Participaron en la investigación veintiséis mujeres que cumplían con los requisitos de ser profesionales, residir en Lima, no haber sido (hasta el momento de la entrevista) madres por propia decisión — es decir, que no tuvieran problemas reproductivos - y estar en el rango de edad de 28 a 38 años. Todas ellas eran económicamente activas (con un rango de ingresos mensuales de entre 900 a 12000 soles); algunas eran casadas; otras, solteras con o sin pareja. La mayoría

2 Un estudio sobre maternidad postergada y rechazada en un grupo de mujeres profesionales académicas de una universidad alemana (Kemkes-Grottenthaler, 2003) sugiere que no se trata necesariamente de un rechazo a la maternidad, pero sí de una decisión difícil en la que tienen que optar entre sus metas profesionales y la reproducción. 
de las entrevistadas vivía de sus ingresos económicos o compartiendo gastos con la pareja o los padres (esto dependía de con quiénes vivía al momento de la entrevista) $)^{3}$. Se escogió mujeres profesionales, porque este grupo muestra cambios en la la tasa de natalidad (ENDES 2013). Nos ceñimos a Lima porque es la ciudad más desarrollada del país, porque aquí se observan mejor los cambios en las perspectivas de vida de las mujeres y porque presenta la mayor proporción de mujeres con educación superior en el país. La razón por la cual se escoge el rango de 28 a 38 años responde a que es este el momento en que las mujeres suelen cuestionarse la decisión de ser o no madres. A los 28 años, la mayoría de las mujeres que accedió a estudios superiores ya los ha culminado o se encuentra inserta en el mundo laboral. Por otro lado, los enfoques médicos señalan que, a partir de los 35 años en adelante, los embarazos pueden calificarse de alto riesgo por las consecuencias en los cambios biológicos de la mujer (Paredes, 2013). A los 38 años, entonces, la posibilidad de que una mujer quede embarazada se considera de alto riesgo.

\section{MATERNIDAD}

Partiremos con Simone de Beauvoir (2009) para recordar que la condición genérica de mujer no es biológica, sino una construcción social. Una construcción que busca naturalizar ciertos comportamientos y funciones sociales como propios de la femineidad, entre ellos, la maternidad, la cual se entendía (y muchos todavía entienden) no solo como función biológica, sino como un derrotero de la realización femenina, puesto que se considera instintiva. Ya Beauvoir (2009) indicaba que no existe tal instinto y que el ejercicio de la maternidad varía en cada mujer y obedece a distintos factores. Badinter (1985), en una revisión histórica de la maternidad en el caso francés, cuestiona el mito del instinto materno. La autora señala que la manera en que se define la maternidad ha ido cambiado a medida que se modificó el rol de la mujer en la sociedad. Sustentada en la crítica feminista, Badinter indica que el amor materno no es algo natural, sino que

\footnotetext{
3 Para esta investigación no se utilizó «clase media» como categoría de análisis, porque en la actualidad peruana es difícil definirla debido a la heterogeneidad de ingresos económicos de los individuos de tal clase (Franco y Hopenhayn, 2010). Desde el área del marketing y la publicidad, Rolando Arellano $(2013,2014)$ propone hablar de «clase media tradicional» (CMT) y «clase media emergente» (CME), pero en tal división se pierden matices de dichos sectores. Otros autores, como Leon, Espíndola y Sémbler (2010), prefieren hablar de «clases medias» o «sectores medios».
} 
es impulsado por una fuerte presión social que relega a la mujer a los roles de reproductora y criadora.

En esta misma línea de pensamiento, Witting (2006) critica la categoría «sexo», producto de una sociedad heterosexual, que impone a las mujeres la obligación de «reproducir la especie». Este sistema heterosexual, argumenta Wittig, genera un sistema de explotación económica por el cual el hombre se apropia del trabajo «por naturaleza» asociado a la maternidad, la crianza de los hijos y las tareas domésticas. Algunos estudios psicoanalíticos señalan que en la psique femenina se internaliza e impone, de manera progresiva la identificación de la femineid4d con la maternidad (Chodorow, 1979; Robles, 2012). Esta ideología, además, es legitimada por instituciones como la escuela, los medios de comunicación y la familia. No obstante, como señala Lipovetsky (1999), la maternidad también dota a las mujeres de poder y autonomía en el mundo privado. Según Lipovetsky, no se trataría solamente de que los hombres no quieren la crianza de los hijos, sino de que las mujeres obtienen un «provecho subjetivo» de esta: el saberse indispensables en la formación del presente y futuro de un niño. De esta manera, aunque la maternidad y las tareas domésticas restan posibilidades a la mujer de asumir posiciones jerárquicas en el mundo social, le proveen otro tipo de sentido y poder. Por ello, para el autor, la maternidad, como función, continuará constituyendo durante mucho tiempo todavía un obstáculo sustancial para la homogenización de los roles sexuales. La maternidad sitúa indefectiblemente a la mujer con el ámbito privado de la vida, argumenta Lipovetski. Empero, la mujer moderna es dueña de dos ámbitos: del público, a través de su profesión y trabajo, y del privado, que parece no querer abandonar.

Los estudios sobre mujeres en la ciudad de Lima nos permiten rastrear las concepciones sobre la maternidad y cómo han ido cambiando en los últimos cuarenta años. En la década de 1960 del siglo XX, la maternidad era la cualidad que, para la entonces clase media limeña, definía la femineidad, según explica Barrig (1979), y la mujer encontraba en el espacio doméstico su lugar. Cornejo Chávez (1960), citado por Barrig $(1979$, p. 29), indica que a la mujer le correspondía atender y velar por el clima moral de la familia, la educación y el bienestar de los hijos y del propio marido. El modelo de la madre es el modelo mariano (Fuller, 1998), de fortaleza, amor y superioridad moral. Este modelo tiene preponderancia hasta la década de 1970. Fuller (1998) señala que, con el pasar del tiempo, el papel de

4 En ello coinciden las profesionales en Lima con las de Caracas y Santiago de Chile del trabajo de Montilva (2008, p. 72). 
la madre irá perdiendo terreno sobre los roles de la crianza y educación de los hijos, porque estos comienzan a ser asumidos por instituciones especializadas, $\mathrm{y}$ aunque la maternidad sigue siendo la labor más importante de la mujer de clase media, ya no ocupa todas sus energías. Además, según la autora, las mujeres en la década de 1980 tenían menos hijos, vivían más, y los hijos pasaban mucho más tiempo en la escuela, de modo que la maternidad activa se vio reducida a una quincena de años. Empero, la madre sigue manteniendo una relación cercana con los hijos ${ }^{<?}$.

Castro Bernardini (2005) indica que, para las profesionales de inicios del siglo XXI, la maternidad sigue siendo importante y es considerada parte del proyecto personal, aunque no incompatible con el proyecto profesional; empero, persisten conflictos y tensiones. Las ideas sobre la maternidad en las mujeres profesionales con las que trabajó Castro Bernardini son similares a las de las generaciones anteriores, pero lo novedoso es que algunas de sus entrevistadas se plantean la opción de no pasar por esta experiencia.

Barrig (1979) y Fuller (1998) trabajaron con mujeres de la clase media limeña, cuyo panorama económico y social era más homogéneo que el de nuestras entrevistadas. Las mujeres que presentan Barrig y Fuller, aunque con diferencias generacionales, inician la maternidad cuando se está cursando estudios universitarios. Por su parte, Castro Bernardini (2005) trabajó con profesionales de universidades particulares, quienes, aunque, más centradas en sus profesiones, también inician la maternidad finalizando sus estudios profesionales. Para las mujeres que aparecen en los trabajos de estas investigadoras, la maternidad ocurre dentro de la segunda década de sus vidas. En contraste, las profesionales entrevistadas para esta investigación provienen de situaciones económicas y sociales heterogéneas y la mayoría de ellas considera que los primeros años de la tercera década de vida son los más adecuados para decidir ser madres, porque les hace falta insertarse en el sector laboral y conseguir cierta estabilidad laboral antes de asumir este cambio.

\section{«EL CRONOGRAMA ESTABLECIDO»Y LAS CONCEPCIONES SOBRE MATERNIDAD}

Al menos la mitad de las profesionales entrevistadas considera que no deberían superarse los 35 años para ser madre, pues se necesita «vitalidad» para criar a un hijo. Es en los treinta cuando se cumple «el cronograma establecido». Como señaló Camila: «Si haces el cronograma que normalmente se espera: sales a los dieciséis [del colegio], a los diecisiete estás en la universidad, a los veintitrés ya 
estás terminando, título veinticuatro, maestría a los veintiocho, a los treinta tienes ciertas bases para tener un sueldo relativamente bueno que te dé cierta estabilidad y no estás ni muy joven ni muy vieja. Treinta, treinta y uno o treinta y dos».

La mayoría de las mujeres han adoptado como propios los discursos médico y psicológico sobre maternidad según los cuales la estabilidad económica y emocional son requisitos importantes para ser madre. A su vez, la estabilidad emocional está relacionada con su realización como individuos ${ }^{<?>}$. En la Lima de inicios del siglo XXI, las profesionales de las distintas «clases medias» se orientan a la búsqueda de la estabilidad económica como requisito previo a la maternidad.

En menor medida fueron señalados los aspectos de la salud de la futura madre y el entorno social y afectivo. En ese sentido, la figura paterna se consideró como un elemento deseable, pero no imprescindible. Por otro lado, las profesionales son conscientes de que la maternidad está limitada por factores biológicos, pero indicaron que esta depende de la decisión de cada mujer. Una de las principales preocupaciones de muchas entrevistadas radica en la vitalidad que puedan tener para dedicarse a la abnegada función de criar a un niño. De ahí que, al menos la mitad de las entrevistadas, señalen un rango de edad que no debería superar los 35 años; mientras que las otras se dividen entre las que consideran que la edad no es relevante y las que manifiestan no querer tener hijos. Como veremos más adelante, esta preocupación se vincula también con la concepción, bastante generalizada, de que la maternidad es principalmente biológica, o sea, el acto de engendrar.

Según lo indicado por la mayoría de entrevistadas, el «cronograma establecido» para la maternidad ha variado en la edad: ya no es la segunda década de vida (como parece ser el sentido común de las mujeres en los trabajos de Barrig, Fuller y Bernardini), sino la tercera década. Esta (re)programación de la maternidad obedece a una representación de la mujer profesional que no pone en cuestión su inserción en el mundo laboral; tampoco espera que el esposo o pareja sea el proveedor (en el testimonio antes citado de Camila, ni siquiera se menciona el matrimonio o la pareja dentro del cronograma).

\section{MODALIDADES DE MATERNIDAD: LA «MAMÁ GALLINA»Y SUS CONTRAPARTES, LA ADOPCIÓN Y EL EMBARAZO NO PLANIFICADO}

Fuller (1998) señala que, para las mujeres de la década de 1970 (de su muestra), la maternidad era entendida como la principal fuente de afectos y satisfacciones. Se trata de una generación de la antigua clase media limeña que vive el tránsito de la mujer como madre-esposa y «reina del hogar» a la mujer que debe salir 
a trabajar para completar el presupuesto familiar. Las mujeres de esta investigación, empero, consideraban a la maternidad como la principal vía de realización. Las de la generación de 1980 — continúa Fuller-adjudican más importancia al desarrollo profesional y tienen un estilo de vida más centrado en ellas mismas. Son las mujeres de esta última generación las que viven la tensión de equilibrar el trabajo con la maternidad, ya sea renunciando al primero o tratando de integrar ambas actividades a su vida. No obstante, en ambas generaciones la maternidad es entendida como la labor más importante, gratificante y la principal vía de realización femenina. Aun las mujeres que adoptan discursos más modernos muestran fuertes rasgos tradicionales, pues «el asignar a la mujer la responsabilidad de los afectos, multiplica sus tareas y la identifica con la esfera privada» (Fuller, 1998, p. 205). Kogan (1994), en su trabajo con mujeres egresadas de la Universidad del Pacífico, indica que la maternidad plantea un dilema para las profesionales, pues dedicarse a la atención de los hijos implica postergar sus aspiraciones laborales, e incluso económicas. En la mayoría de casos, las mujeres optan por ser madres en desmedro de sus labores profesionales, porque, según señala Kogan, la maternidad sigue siendo un eje importante en la identidad femenina. Ya en la década de 1990 algunas mujeres optaban por los negocios o trabajos independientes para poder cuidar a sus hijos, según esta autora, pero son trabajos con menor exigencia de tiempo y baja remuneración.

Aunque conscientes y orgullosas de sus capacidades profesionales, la mayoría de las mujeres de esta muestra se siguen identificando con el modelo tradicional de maternidad. Al interrogarles por cómo se «ven» como madres, muchas respondieron que se imaginan como la «mamá gallina». Las características que resumen esta frase son: un involucramiento pleno en la crianza y cuidado de los hijos, su acompañamiento, la sobreprotección.

Mamá gallina [risas]. Una de las razones por las que yo busco trabajar como independiente es justamente para disponer de un tiempo adecuado para, cuando me toque ser madre, poder estar con mis hijos. Poder disfrutar de esa libertad de que tú manejes tus horarios, para poder estar con ellos (Cattleya).

Las contrapartes de la «mamá gallina» son diversas. Algunas desean romper con la sobreprotección que caracterizó a sus madres. Tiresias, por ejemplo, propone un modelo de «maternidad equilibrada». Según señala la extrema, cercanía con los hijos puede resultar asfixiante. «No quisiera ser una madre lejana ni distante. Pero también me gustaría que mi hijo se sintiera libre de tomar sus decisiones o de no sentir ningún tipo de presión emocional debido a mi causa» (Tiresias). Por su parte, 
Catalina se imagina como una «madre intelectualoide», comprando libros para su hijo pequeño y contribuyendo a desarrollar su independencia y a «la exploración del mundo». Sara, en cambio, se concibe como una «madre relajada», que no desespera ante las exigencias de su hijo ni ante las suyas propias. También están aquellas que no se sienten preparadas para la maternidad, de allí que se avizoraran como «madre desastre» (Carmen, Arándano y Eugenia) o «madre improvisada» (Teresa). Carmen y Eugenia, de su lado, consideran que no cuentan con el requisito de la estabilidad emocional, pieza clave cuando se plantean la maternidad.

\section{MATERNIDAD: RENUNCIA Y SACRIFICIO}

El modelo de la «mamá gallina», el más referido por las entrevistadas, se sustenta en la noción de maternidad que les fue transmitida, enseñada. Esta es una labor de crianza cuya responsabilidad recae principalmente en la mujer. Las ideas más recurrentes de este tipo de maternidad son la renuncia a otros campos de la vida, el «vivir para otro», la expresión de un «amor incondicional». Aún las mujeres que plantearon otros tipos de maternidad, consideraron que esta labor es de gran responsabilidad y requiere especial atención y renuncia, sobre todo al tiempo personal.

Al responder si dejarían temporal o permanentemente alguna actividad por causa de la maternidad, la mayoría indicó que sí renunciaría temporalmente a su trabajo. Dado que esta es su principal actividad, así como la fuente de sus ingresos económicos, tal dimisión afectaría significativamente sus vidas. Empero, la renuncia se entiende como parcial o temporal. Ninguna de las mujeres entrevistadas se mostró dispuesta a abandonar totalmente sus actividades laborales. Otras posibles renuncias tienen que ver con las capacitaciones laborales y las actividades de goce individual, como los estudios y los viajes. Ello se debería no solo al tiempo invertido (o la falta de él), sino por la conciencia de los gastos que acarrea la crianza de un hijo. Para otras mujeres, la «inminente» renuncia les genera conflicto, como a Pamela quien admitió que «no quisiera renunciar a nada. Ese es uno de mis conflictos por tener un bebé, renunciar a las cosas que me he trazado».

En nuestra lectura de las entrevistas identificamos que la maternidad se entiende como renuncia y sacrificio ${ }^{5}$, aunque se argumenta de dos maneras

Sacrificio en la séptima acepción del diccionario de la RAE señala: m. Acto de abnegación inspirado por la vehemencia del amor. Es decir, se trata de una renuncia de las pasiones, deseos, intereses propios en función de otro. Es en este sentido que se utiliza el término «sacrificio». 
diferentes. La primera línea argumentativa la denominamos «sacrificio aprendido», y la segunda, «sacrificio instintivo». La primera hace referencia a lo que algunas profesionales describen como su experiencia de hijas y espectadoras de la maternidad. Consideran que se trata de un cambio radical que comienza por el propio cuerpo y para el cual se requiere una especial madurez en tanto implica aceptar una responsabilidad «de por vida». Esta responsabilidad implica varias renuncias que pueden ser entendidas como sacrificio. «A nosotras sí nos dicen, la madre se sacrifica, la madre motiva, la madre da, la madre cobija, la madre alimenta. Entonces, yo pienso que, si soy un niño varón, y escucho que le dicen eso a mi hermana, definitivamente yo la paso muy lindo, porque siendo padre yo solamente engendro al hijo y trabajo para mantenerlo, porque eso sí les dicen: tienes que trabaja6 para mantener a tu familia y ahí queda» (Irene). «Mi abuela podría haber sido una gran costurera de no haber conocido a mi abuelo. Mi madre hubiera podido tener su clínica de no habernos tenido» (Eugenia).

El «sacrificio instintivo», en cambio, se refiere a la noción de la maternidad como instinto. En ese sentido, dado que no sería elegible otra forma de maternidad más que la entrega total, las profesionales de este grupo prefirieron no usar el término «sacrificio» sino eufemismos: «amor brindado de modo desinteresado», «una abnegación bárbara»o «dedicación». Todas estas frases implican, no obstante, dejar de lado ciertas actividades, pero en palabras de estas mujeres, porque a las madres «les nace». Nuevamente el factor tiempo para integrar las actividades laborales y la crianza de los hijos sale a relucir. Leona indicó que la maternidad implicaría «organizar los tiempos y equilibrar ciertos momentos en que los niños necesitan tiempo». Las profesionales utilizaron frases como «dedicación exclusiva», «tiempo completo», «especial y complejo proyecto de vida» para hablar de las exigencias que para ellas implica la maternidad.

Sea que entiendan este sacrificio como algo aprendido o algo instintivo, exigiría de la mujer renuncias a su vida pública — principalmente en la dimensión laboral—, al menos durante los primeros años de vida del hijo o hija. Estas ideas revelan que las profesionales todavía adjudican la labor de crianza y cuidado de los hijos a la mujer. Algunas profesionales, como las de la generación de 1980 que estudió Fuller, sienten el conflicto de intentar integrar la titánica labor de madre

6 Si bien no tener hijos ser percibe como «una falta» en la realización de la mujer, más grave aún sería la confirmación de una tendencia homosexual. Pamela comenta: «Yo tengo treinta e imagínate, todas mis tías ya quieren que sea mamá. Y me he peleado con casi todas. A una le dije que era lesbiana (risas). No me volvió a preguntar nada». 
con sus trabajos. Otras, las que llamaremos «grupo disidente», se cuestionan si están en la capacidad de hacerlo o, más aún, si realmente desean hacerlo.

En el «grupo disidente» estarían algunas profesionales que no se sienten dispuestas a seguir (o cumplir) el modelo de sacrificio, no se sienten capaces de ser la «mamá gallina» ni ningún otro tipo de madre. Entre las «disidentes» se encuentran mujeres que centran su realización y proyectos de vida en sí mismas. No obstante, al ser la maternidad una importante fuente de reconocimiento social, las «disidentes» perciben en esta diferencia cierta culpa y se autodenominan «egoístas». Con este adjetivo tratan de calificar las dudas que tienen sobre su capacidad de dejar de lado proyectos personales para dedicarse a la crianza de niños. Como ya señalamos, la idea del instinto materno es muy recurrente en las respuestas, por ello, quienes asumen que existe tal instinto generan más contradicciones en sus apreciaciones sobre la maternidad. No obstante, asuman la maternidad o no, la noción de instinto sirve para justificar tanto los anhelos maternales como la falta de ellos: «Sería un desastre, soy muy relajada, soy muy ansiosa, creo que no tengo el instinto» (Arándano).

\section{«¿Y TÚ, CUÁNDO?» PRESIÓN SOCIAL}

Ahora bien, si estas mujeres entre los 28 y 38 años afirman que la maternidad no es la única ni máxima vía de realización femenina, el entorno en el que viven todavía considera que las mujeres deben aspirar a ser madres. Las expectativas de los padres, sobre todo de las madres, están puestas en la capacidad reproductiva de las hijas, y así, la mayoría de ellas son asediadas con preguntas y comentarios sobre su decisión de postergar la maternidad, de renunciar a ella o simplemente de no ser madres todavía. «Sí. He sentido la presión. De parte de la familia. Sobre todo de mamá. Sí, de ella. Lo dice con cariño, pero presiona. Aunque nunca he dejado que esa presión me aturda» (Úrsula). Estos comentarios y preguntas muchas veces vienen de entornos que rebasan los límites familiares y se extiende a los amigos, «isobre todo las mujeres!», se sorprende Andrea.

Entre las preguntas y comentarios incómodos sobre la ausencia de hijos, suele enunciarse la pregunta «¿y tú, cuándo?». Con esta interrogante se cuestiona la edad de la mujer que, habiendo terminado sus estudios superiores y logrado la estabilidad laboral («el cronograma establecido»), no se ha decidido a ser madre o simplemente no ha encontrado el contexto adecuado para serlo. Parece ser que el entorno familiar y amical de las profesionales considera como parte del rol femenino la maternidad, sin tomar en cuenta bajo qué condiciones se produzca. 
Esta presión parece reivindicar a la edad como requisito único para la maternidad: «[Me dijeron que, si espero mucho, mis hijos me] van a decir abuelita» (Rita, 31 años).

Las mujeres casadas reciben una presión aún mayor, como cuenta Diana, quien después de tres años de matrimonio sin hijos escucha de su familia «el pedido»; sin embargo, ella tolera los comentarios porque «dentro de todo sé que lo hacen en buena onda, no han sido muy insistentes». Esta presión a veces trata de validarse con argumentos científicos, como contó Estela (quien convive con su pareja), a quien sus amigos le advierten los peligros de ser una «madre añeja». Este tipo de comentarios genera preocupación: «Se han burlado. Y tal vez por ese lado, el susto de que ¡uy!, no vaya a ser que no pueda tener hijos» ${ }^{7}$.

Estos reclamos y presiones parecen tener otro asidero simbólico importante: se trata del reconocimiento social que obtiene la mujer-madre. Una mujer profesional destacada, independiente, trabajadora, e incluso realizando una labor social y política parece no ser tan reconocida ni considerada como la mujer que ha «cumplido» su rol de madre para con la familia de origen y la sociedad.

Sobre el reconocimiento social de la maternidad, las profesionales difirieron en sus respuestas. Se generaron dos tendencias de respuestas: las que consideran que la maternidad sí tiene un reconocimiento social y las que opinan que no lo tiene. El primer grupo lo forma la mayoría de profesionales. Ellas señalan que la madre que cumple su rol abnegadamente es reconocida y considerada socialmente. El grupo que consideró que la maternidad no tiene mayor reconocimiento indicó que, por lo contrario, la sociedad no valora lo suficiente la labor sacrificada de las madres.

\section{NO MATERNIDAD}

En los últimos años se ha hecho más mediática la tendencia de las $\mathrm{NoMo}^{8}$, mujeres que deciden abiertamente no ser madres. Esta es más difundida en las redes sociales, donde las mujeres postean noticias y videos de esta línea. También los medios de prensa nacionales han dado cuenta de este estilo (Núñez, 2014; Yrigoyen, 2015). «Opción válida», dice un artículo de Hildebrandt, y relata tres historias de mujeres que decidieron no ser madres «a pesar de la presión social».

7 Si bien no tener hijos ser percibe como «una falta» en la realización de la mujer, más grave aún sería la confirmación de una tendencia homosexual. Pamela comenta: «Yo tengo treinta e imagínate, todas mis tías ya quieren que sea mamá. Y me he peleado con casi todas. A una le dije que era lesbiana (risas). No me volvió a preguntar nada».

8 Del inglés «No mother». 
«La rebelión de las 'no madres'», titula La República para divulgar el caso de tres mujeres «jóvenes, profesionales y saludables», pero con un «plan de vida que no incluye la maternidad».

Todas la entrevistadas afirmaron que la no maternidad es una opción de vida que debe ser respetada, pero las posturas que asumieron ante esta alternativa son diversas. Casi gradualmente se puede encontrar tres grupos de opinión: en el primero, las mujeres que, respetando la opción de la no maternidad, dicen no entenderla ni compartirla; un segundo grupo al cual le parece admirable la decisión de la no maternidad, aunque no la consideran como una opción para ellas, $\mathrm{y}$ un tercer grupo que se considera como parte de esta tendencia.

Respetaría su decisión, pero me parece un poco ilógico [...] la mujer ha sido creada para procrear. Una de las funciones de la mujer es procrear. Debe ser una sensación muy especial, muy bonita. Y perderse esa sensación por un tema sociocultural sería algo inútil. [¿Con qué te refieres a «sociocultural»?] Porque hay muchas mujeres que no quieren tener hijos para no dejar de ser mujeres, dejar de salir a fiestas, de tener varias parejas, de repente. O simplemente por no ser madres solas, solteras, o madres divorciadas. El prejuicio de la sociedad, o la cultura de ser libres, a estar «encerradas» en casa por un bebé como que las limita mucho. A eso es lo que me refiero (Marisol, del primer grupo).

En el segundo grupo, están las profesionales que simpatizan con la tendencia, aunque no afirmaron a ciencia cierta su deseo de no ser madres. «Las mujeres puedan tomar las decisiones que les convenga, que las satisfaga más a nivel personal en el largo plazo, que más mujeres estén despertando al hecho de que tienen una opción y que por más que le estén poniendo presión no tienen por qué ceder a ella» (Guadalupe). En general, para el segundo grupo de mujeres, la opción de la no maternidad permite, en términos de Sara, mostrar una «sensibilidad nueva de la mujer», que les brinda a ellas la posibilidad de «experimentar nuevas dimensiones suyas. La búsqueda personal, la satisfacción laboral, profesional, la satisfacción de la vida personal, de la compañía de los amigos, son como cosas a las que antes la mujer no tenía acceso». Según Sara, estas son opciones nuevas porque ahora las mujeres no tienen que ser madres tan jóvenes.

En el tercer grupo están las profesionales, para quienes no ser madres es su opción de vida.

Me considero parte de ese público, en realidad. Yo siempre me considero parte de las «neosolteras» o de las «no mamás». Me parece que es una revaloración del papel de la mujer en la sociedad. Antes era bien raro que la mujer 
tenga esa posibilidad, pero ahora que estamos teniendo más protagonismo en las empresas, en la misma política, comenzamos ya a revalorar las cosas y ya dejamos algunas. $\mathrm{Y}$ eso simplemente me parece muy interesante, me parece bueno también (Guadalupe).

\section{PATERNIDAD}

En cuanto a la participación masculina en la crianza, la totalidad de entrevistadas consideró que debe ser una tarea conjunta en la que participan madre y padre. Se señalaron como características importantes de un buen padre el afecto y la capacidad de poder demostrarlo a sus hijos. Ahora bien, sobre la figura paterna y las características que debe tener, las respuestas permiten configurar dos ideas generales de paternidad. Por un lado, la que considera que no existe mayor diferencia en la labor de crianza entre la madre y el padre, y que, por ende, el padre debería estar dispuesto a la renuncia de actividades en pro de los hijos. «Si las mujeres tenemos que sacrificar tiempo, ¿los hombres, por qué no? Si de algo estoy convencida, es que hay que sacrificar tiempo. Y eso debe ser 50-50, igual que todas las actividades, todos los gastos, todo» (Carmen).

La segunda idea, en cambio, sí atribuye características particulares a la paternidad y considera que, más que renuncia, el padre debe organizar bien sus tiempos para compartir junto a los hijos. Entre las características particulares de la paternidad algunas mencionaron: ser «ejemplo a seguir» (Emilia), ser «un guía, un modelo» (Úrsula) en la «formación, sobre todo moral, de principios» (Cattleya); también la figura masculina se asocia a la protección, a la seguridad, el padre sería el encargado de «sacar la cara por los hijos» (Irene).

En esta segunda tendencia, el padre no tiene el mismo nivel de renuncia a su tiempo libre que se espera de la madre. Su participación en la crianza de los hijos se resolvería por la conciliación de sus tiempos personales, labores con el tiempo que debe dedicar a los hijos. «[Puede] ir a jugar fútbol, salir con amigos, [pero sí deberían dedicarles tiempo a los hijos]. Quizá para poder compartir fines de semana o dentro de semana. Luego de cumplir su rol de trabajo debe llegar a casa y compartir con la familia» (Leona).

Ahora bien, acerca del asunto de las renuncias, algunas otras entrevistadas se inclinaron a pensar que estas dependen de las necesidades de los hijos y que siempre se puede negociar con la pareja: «Depende en qué condición se encuentren. Se evalúa» (Catalina). «Con mi pareja evaluaríamos, si el hijo requiriese atención personalizada todo el tiempo, cuál de los dos renunciaría a su trabajo» 
(Sara). Esta evaluación sobre las renuncias, siempre entendidas de manera temporal, dependería de los ingresos económicos, es decir, de que estos no se vieran mermados. «Porque de todos modos de algo va a tener que vivir» (Pamela).

\section{MATERNIDAD Y FEMINEIDAD: DILEMAS Y CONTRADICCIONES}

Como se señaló líneas arriba, la maternidad se concibe de dos formas, como vínculo que se construye y como instinto. En la primera línea, la maternidad es un vínculo que se construye. Pero también cabe la posibilidad de que la mujer no quiera construir dicho vínculo, de ahí que sea elegible y que la opción de no ser madre resulte válida y coherente. La segunda línea, en cambio, entiende la maternidad como instinto, lo cual genera ciertos dilemas o contradicciones, pues la totalidad de las profesionales admitió que la maternidad es una elección personal y que, no le suma ni resta a la femineidad. Entonces, ¿puede un instinto ser elegible? Irene, bióloga, argumentó que sí, pero que el ser humano no tiene por qué realizar todos sus «deseos». Cattleya, quien señaló que a todas las mujeres «nos nace» el deseo de ser madres, admitió después que la maternidad /paternidad es un vínculo construido, que remite en realidad a la crianza de otro ser y no solo a su procreación.

Trabajar con veintiséis voces resulta complejo, porque cada profesional presenta matices particulares sobre sus concepciones de maternidad. No obstante, en un esfuerzo por intentar asir sus respuestas, hemos construido una tabla que procura mostrar las dos tendencias que más se repiten a lo largo de los temas abordados. En esta tabla procuramos observar las diferencias entre las dos tendencias y también la mayor similitud entre ambas: entender la maternidad como sacrificio. Entre estas dos tendencias, hay varias otras maneras de entender la maternidad, que en algunos casos, combinan contradictoriamente características de una y otra columna.

Ahora bien, en ambos lados de la columna la maternidad es considerada como un sacrificio, sea que se entienda como algo instintivo o como vínculo construido. Si el padre participa activamente de la crianza o no, se considera que quien entrega más tiempo y quien más renuncias debe hacer es la mujer. Por eso las «disidentes» son profesionales que cuestionan su propia capacidad o aun voluntad de renuncia. En ningún caso se cuestiona la noción de maternidad como renuncia. Quizás, por el panorama algo pesimista para una mujer profesional, la maternidad sea una opción de vida para ser pensada y cronogramada con cuidado. 


\section{Ideas sobre la maternidad}

\section{Más tradicional}

\section{Mujer heterosexual}

Considera maternidad como instinto.

Considera la maternidad como sacrificio naturalizado.

Dispuesta a asumir los roles domésticos y la mayor parte de la crianza del hijo.

Considera que el padre es el soporte económico y moral de la familia y que no debe hacer mayores renuncias por los hijos.

\section{Más moderna}

\section{Mujer heterosexual}

Considera la maternidad como vínculo construido.

Considera la maternidad como sacrificio aprendido y al que no está dispuesta, es una disidente.

Considera que los roles domésticos deben ser compartidos.

Considera la paternidad como un rol similar a la maternidad y que el padre debe estar dispuesto a renuncias por sus hijos.

Úrsula, quien rebasa el rango de edad propuesto en el trabajo (tenía 39 años cuando la entrevista), era madre después de haberse propuesto otros proyectos de vida y de conseguir realizar gran parte de ellos. Las demás mujeres, entre dubitativas y decididas, no eran madres por su propia voluntad.

Me gustaría decir que yo decidí ir postergando mi maternidad porque quería hacer muchas cosas antes... y, bueno, esa es mi opinión. No quiere decir que yo tenga la razón. Puede haber personas que quieran iniciar más temprano su maternidad. Simple y llanamente creo que cada persona debe conocerse lo suficiente como para saber qué es lo que quiere hacer con su vida y cómo llevarlo a cabo. Y hacerlo sin pensar en lo que los demás están haciendo o en el entorno, que muchas veces te presiona, sobre todo en las mujeres. Tenemos libertad (Úrsula).

\section{AMODODECONCLUSIÓN. ¿PORQUÉ POSTERGAMOS LAMATERNIDAD?}

Las mujeres que participaron en esta investigación provienen de distintas formaciones académicas, con historias familiares diferentes, y tienen, no obstante, ideas convergentes sobre la maternidad. Las que se animaron a participar en este trabajo lo hicieron interesadas por el tema, pues las interpela directamente. Como señalamos, la maternidad les plantea una disyuntiva. Tanto las profesionales «disidentes» como las que desean ser madres entienden la maternidad como 
sacrificio y renuncia del tiempo personal: ellas deben optar entre asumirla o no como un proyecto de vida, conscientes del cambio radical que esta les acarrearía.

Las mujeres participantes en esta investigación estiman que el tiempo y la calidad del mismo son factores determinantes en la crianza. El tiempo dedicado a la crianza compite con el tiempo del ejercicio profesional; por ello, responder a este «modelo base» resulta difícil y no todas están seguras o dispuestas a dejar de lado sus logros individuales para hacer frente a la responsabilidad que implica ser madre.

Es importante señalar que estas mujeres valoran la libertad que tienen de escoger si desean o no ser madres, y en caso de desearlo, las condiciones en las que se quiere serlo (económicas, emotivas, de pareja). Cualquiera sea su elección, se trazan una serie de metas (estudios, mundo laboral, ocio) que encaminan a búsqueda de mejores condiciones económicas — si desean ser madres - o a una búsqueda de realización personal. En ambos casos se necesita tiempo, tiempo para lograr la estabilidad económica, la independencia laboral y poder conciliar maternidad, trabajo y vida personal, o tiempo para buscar en otras decisiones la realización femenina.

\section{REFERENCIAS}

Aramburú, Carlos E. y María Bustinza (2007). La transición demográfica peruana: implicancias para la conciliación trabajo-familia. Economía y sociedad, 63, 62-73. Recuperado de http://www.cies.org.pe/sites/default/files/files/otros/ economiaysociedad/07-aramburu.pdf

Arellano, Rolando (2013). Los nuevos peruanos solo han vivido épocas de crecimiento. Gestión, 8 de octubre de 2013. Recuperado de http://gestion.pe/economia/rolandoarellano-nuevos-peruanos-solo-han-vivido-epocas-crecimiento-2078044

Arellano, Rolando (2014). Cómo nace la nueva clase media. El Comercio, 7 de abril del 2014. Recuperado de http://elcomercio.pe/opinion/rincon-del-autor/como-nacenueva-clase-media-rola904

Arellano, Rolando (2016). Viene la otra primavera. Recuperado de http://www.arellanomarketing.com/inicio/viene-la-otra-primavera/ 29 de marzo de 2016.

Badinter, Elisabeth (1985). Um amor conquistado: o mito do amor materno. Trad. Waltersin Dutra. Rio de Janeiro: Nova Fronteira.

Barrig, Maruja (1979). Cinturón de castidad. La mujer de clase media en el Perú. Lima: Mosca Azul. 
Castro Bernardini, María del Rosario (2005). Mujeres profesionales jóvenes: redefinición de los roles tradicionales femeninos. Tesis para optar la licenciatura en Sociología. Lima: Pontificia Universidad Católica del Perú.

Cepal (2007). El envejecimiento de la población mundial es inevitable En Estudio Económico Mundial Social Recuperado de http:/www.cepal.org/prensa/noticias/comunicados/5/28935/wess07factsheetSP.pdf. 5 octubre 2014.

Chacón, Fernanda y Marcela Tapia (2017). No quiero tener hijos(as)... continuidad y cambio en las relaciones de pareja de mujeres profesionales jóvenes. Polis Revista Latinoamericana, 46(16), 193-220. Recuperado de https://www.researchgate. net/publication/318558184_No_quiero_tener_hijos_as_continuidad_y_cambio_ en_las_relaciones_de_pareja_de_mujeres_profesionales_jovenes

Chodorow, Nancy (1979). The reproduction of mothering. Psychoanalysis and the Sociology of Gender. Los Angeles, CA: University of California Press.

Delgado, María Teresa y Domingo Gómez (2006). «Dinkis»: marcando un nuevo estilo de vida. Revista Científica de Comunicación y Educación, (26). Recuperado de http://rabida.uhu.es/dspace/handle/10272/1292

Franco, Rolando y Martín Hopenhayn (2010). Las clases medias en América Latina: historias cruzadas y miradas diversas. En Rolando Franco, Martín Hopenhayn y Arturo León (eds.), Las clases medias en América Latina: retrospectiva y nuevas tendencias (pp. 7-41). México D.F.: Siglo XXI Editores.

Fuller Osores, Norma (1998). Dilemas de la femineidad. Lima: Pontificia Universidad Católica del Perú.

Instituto Nacional de Estadística e Informática (2014). PERÚ: Encuesta Demográfica y de Salud Familiar-ENDES 2013 Nacional y departamental. Lima: Dirección Técnica de Demografía e Indicadores Sociales. INEI.

Kemkes-Grottenhaler, Ariane (2003). Postponing or rejecting parenthood? Results of a survey among female academic professionals. Journal of Biosocial Science, $35(02), 213-226$.

Kogan, Liuba (1994). Profesionales, esposas y madres. Egresadas de la Universidad del Pacífico. 1980-1985. Apuntes 35. Revista de Ciencias Sociales, (35), 97-107. https://doi.org/10.21678/apuntes.35.406.

Kogan, Liuba (2009). Regias y conservadores. Mujeres y hombres de clase alta en la Lima de los noventas. Lima: Fondo Editorial del Congreso del Perú.

León, A. Espíndola, E. y Sémbler, C. (2010). Clases medias en América Latina: una visión de sus cambios en las dos últimas décadas. En Franco, Hopenhayn y León (eds.), Las clases medias en América Latina: retrospectiva y nuevas tendencias (pp. 43-103). México D.F.: Siglo XXI Editores. 
Lipovetsky, Gilles (1999). La tercera mujer. Permanencia y revolución de lo femenino. Barcelona: Anagrama.

Montilva, María (2008). Postergación de la maternidad de mujeres de dos metrópolis latinoamericanas. Utopía y Praxis Latinoamericana, 13(41), 69-79.

Núñez, A. (5 de octubre de 2014). La rebelión de las 'no madres'. Domingo. La República, 14-15.

Paredes Pérez, Napoleón (2013). Maternidad postergada. Horizonte Médico, 13(1), 45-50.

Robles Blaessinger, Rodrigo (2012). Maternidad ¿un deseo femenino en la teoría freudiana? Nomadías, 16, 119-135. Noviembre. Recuperado de http://eds.b.ebscohost. com.ezproxybib.pucp.edu.pe:2048/eds/pdfviewer/pdfviewer?sid=02ea60630df1-4f5b-967c-588cdcac2402\%40sessionmgr112\&vid=2\&hid=103

Therborn, Göran (2007). Familias en el mundo. Historia y futuro en el umbral del siglo XXI. En Irma Arriagada (coord.), Familias y políticas públicas en América Latina (pp. 31-61). Santiago de Chile: Cepal y UNFPA.

Torricelli, Orlando (2018). Elevadas tasas de embarazo adolescente en América Latina. Recuperado de http://es.rfi.fr/americas/20180314-el-embarazo-adolescente

Wittig, Monique (2006). El pensamiento heterosexual y otros ensayos. Barcelona: EGALES.

Yrigoyen, M. C. (15 de mayo de 2015). Opción válida: no ser mamá. Hildebrandt en sus trece, 20-21. 


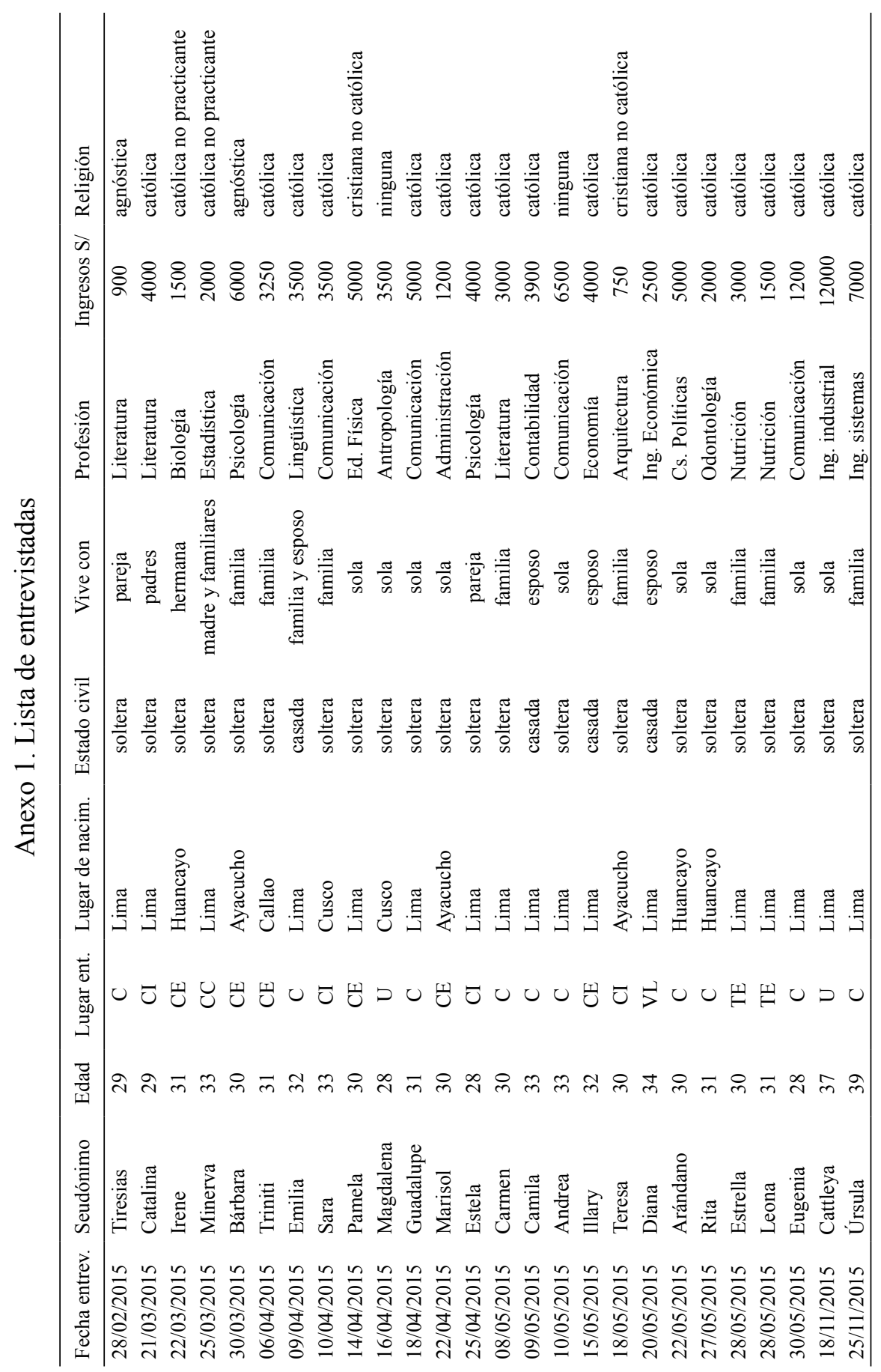

